\title{
Correction to: Forensic evaluation of alleged wrist restraint/handcuff injuries in survivors of torture utilizing the Istanbul Protocol
}

\author{
Miriam Y. Neufeld ${ }^{1} \cdot$ Sarah Kimball ${ }^{1,2} \cdot$ Andrew B. Stein $^{1} \cdot$ Sondra S. Crosby ${ }^{1,2,3}$
}

Published online: 9 June 2021

○) Springer-Verlag GmbH Germany, part of Springer Nature 2021

Correction to: International Journal of Legal Medicine (2021) 135:583-590 https://doi.org/10.1007/s00414-020-02451-5

In the published article, at page 2 , in the sentence "In this study, of all 31 injuries resulting in permanent disability, 24 cases (25\%) of lasting injuries were related to nerve damage from handcuffs [3]." should be change to, "In this study, of all 24 injuries resulting in permanent disability, 6 cases (25\%) of lasting injuries were related to nerve damage from handcuffs [3]."

Publisher's note Springer Nature remains neutral with regard to jurisdictional claims in published maps and institutional affiliations.

The online version of the original article can be found at https:// doi.org/10.1007/s00414-020-02451-5

Sondra S. Crosby scrosby@bu.edu

1 Boston University School of Medicine, 72 E Concord St, Boston, MA 02118, USA

2 Immigrant \& Refugee Health Center, Boston Medical Center, Boston, University School of Medicine, 725 Albany Street, Suite 5b, Boston, MA 02118, USA

3 Boston University School of Public Health, Center for Health Law, Ethics, and Human Rights, 715 Albany St, Talbot Building $3 \mathrm{~W}$, Boston, MA 02118, USA 